\title{
Mindfulness, Resilience and Psychological Distress among Youth in a University Setting
}

\author{
Rituporna Dhar ${ }^{1}$, Arif Ali ${ }^{2}$ Nilesh Maruti Gujar ${ }^{3}$, Banani Baisha ${ }^{4}$, Priyanka Saikia ${ }^{5}$ \\ ${ }^{1}$ M.Phil Trainee, Dept. of Psychiatric Social Work, LGBRIMH, Tezpur, Assam \\ ${ }^{2}$ Assistant Professor, Dept. of Psychiatric Social Work, LGBRIMH, Tezpur, Assam \\ ${ }^{3} \mathrm{PhD}$ Scholar, Dept. of Psychiatric Social Work, LGBRIMH, Tezpur, Assam \\ ${ }^{4} \mathrm{PhD}$ Scholar, Dept. of Psychology, Guahati University, Gauhati, Assam \\ ${ }^{5}$ M.Phil Trainee, Dept. of Psychiatric Social Work, LGBRIMH, Tezpur, Assam \\ Corresponding author: Arif Ali \\ Email - arifalipsw@gmail.com
}

\begin{abstract}
Background: University students experience psychological distress during their first year of joining university and this can have a negative impact on their physical and mental health. Resilience and mindfulness can reduce stress and can help to enhance their coping and wellbeing. To investigate the relationship between mindfulness, resilience and psychological distress among first year undergraduate university students.

Methodology: The cross- sectional study was conducted at Tezpur University, Assam and the University of Science, Technology and Management, Meghalaya. Purposive sampling was used to select the universities. A total of 300 participants were selected for the present study using convenience sampling technique. Sociodemographic data sheet, the Resilience scale, Depression Anxiety Stress Scale-21, and Freiburg Mindfulness Inventory was administered.

Results: In the study, 9.5\% were having moderate level of depression, $6.7 \%$ had a severe level of anxiety and $1.4 \%$ had extremely severe level of anxiety. $15.4 \%$ had moderate level of stress. $3.2 \%$ had a very low level of resilience. Psychological distress had significant negative correlation with mindfulness $(r=-0.229 ; \mathrm{p}$ $>0.01)$ and resilience $(\mathrm{r}=-0.325 ; \mathrm{p}>0.01)$. Resilience (Beta $=-0.283, \mathrm{t}=-4.857 ; \mathrm{p}=0.0001)$ and Mindfulness (Beta $=-0.149 ; \mathrm{t}=-2.566 ; \mathrm{p}=0.01$ ) strongly contributed to the variance on the overall psychological distress (depression, anxiety \& stress).

Conclusion: The findings show resilience and mindfulness are significant predictors of psychological distress among university students. There is a need for resilience and mindfulness-based training programme for the university first year students.
\end{abstract}

Keywords: Mindfulness, resilience, psychological distress, youth.

(Paper received $-5^{\text {th }}$ December 2019, Peer review completed $-28^{\text {th }}$ December 2019)

(Accepted $-29^{\text {th }}$ December 2019)

\section{INTRODUCTION}

Attending university is a particularly stressful time due to changes in environment. First-year college students face developmental and transitional challenges as emerging adults, they are learning many new things in the environment such as maintaining new relationships, managing finances independently, and dealing with various personal, social and academic demands [1]. Psychological distress has a negative impact on students' physical, mental and academic wellbeing [2]. Among university student's high levels of resilience and mindfulness are found to be significant predictors of low levels of psychological distress [3-6]. Resilience has been positively correlated with effective coping styles, whilst negatively correlated with psychological distress [7-8]. Further, Mindfulness practices can serve as a useful tool for adaptive coping for students to 
build academic resilience [1] and also associated with lower psychological distress and increased psychological well-being [9]. Resilience and mindfulness can help students to reduce psychological distress. In enhancing social and personal well-being, adjustment and reducing stress in university students, resilience and mindfulness can act as a protective factor and reduce the likelihood of negative outcomes. Thus, the current study aims to further extend the body of literature with regard to the relationship between mindfulness, psychological distress and resilience among youth in a university setting in North East context. The present study assessed the mindfulness, resilience and psychological distress and find out the extent to which mindfulness and resilience predict the variability in psychological distress among undergraduate students.

\section{METHODOLOGY}

The present study followed the cross-sectional descriptive study design. The participants were first year degree students of from Tezpur University, Tezpur and University of Science, Technology and Management, Meghalaya. Purposive sampling was used to select the universities (Tezpur University, Tezpur, Assam and of Science, Technology and Management, Meghalaya) and simple random sampling method was used to select the participants. Permission was taken from the university and consent was taken from the students to participate in the study. A total of 300 participants were selected for the present study using convenience sampling technique. Out of 300 hundred, 283 data sheets were analysed for the present study, 17 data sheets were rejected due to being incomplete

\section{Ethical considerations}

The study was approved by the scientific committee and institute ethics committee of LGBRIMH, Tezpur.

\section{Data Analysis and Data Interpretation}

Statistical analysis was done using SPSS 25.0 version. Socio-demographic details and prevalence of psychological distress, resilience and mindfulness was analysed by descriptive statistics. Pearson correlation and linear regression was done to find out correlation, predictors in psychological distress.

\section{Measurements}

1. Socio-demographic data sheet: Semi-structured proforma that contained details of demographical information.

2. The Depression Anxiety Stress Scale-21(DASS-21) [10]: The Depression Anxiety Stress Scale (DASS): The DASS is a 42-item self-report inventory that provides scores on three subscales: Depression (14-items), anxiety (14-items), and stress (14-items). Each item was rated on a 5-point scale. The internal consistency alpha coefficients were found for depression $(0.90)$, anxiety $(0.92)$, and stress $(0.92)$ respectively.

3. Freiburg Mindfulness Inventory (FMI) [11]: The FMI is a 14- (short form) or 30-item scale used to measure experiences of mindfulness, non-judgmental present-moment observation and openness to a negative experience. The FMI conceptualizes mindfulness through a Buddhist philosophy, as a state of mind in which an individual pays attention to all internal experiences, such as thoughts, feelings, or attitudes. The FMI is a 14- (short form) is used in the general population. The total score was calculated by adding all the scores on the 14 items of the FMI. Item 13 was reversed scored, Higher scores indicate higher levels of mindfulness. The Cronbach's alpha was 0.93.

4. Ego- Resilience Scale (ER89) [12]: The Ego-Resiliency Scale (ER89) was developed by Block and Kremen and was determined to have an adequate level of internal consistency (Cronbach's $\alpha=$ 0.82). The ER89 is comprised of 14 items, each rated on a 4-point Likert-type scale. Response options range from 1 (does not apply at all) to 4 (applies very strongly). Scores are determined by summing each item, with total scores ranging from 14 to 56 . Score $47-56$ is considered Very Highlevel Resiliency Trait, 35-46 (High Resiliency Trait) 23-34 (Undetermined Trait), 11-22 (Low Resiliency Trait),0-10 (Very Low Resiliency Trait) 


\section{RESULTS}

The table 1 shows 152 (53.7\%) male and 131 (46.3\%) female participants were included in the study. 17 $(6.0 \%)$ of the participants belonged to upper socio-economic class, 121 (42.8\%) participants belonged to upper middle socio-economic class whereas $112(39.6 \%), 22(7.8 \%)$ and $11(3.9 \%)$ participants belonged to lower middle, upper lower and lower socio-economic class respectively. $172(60.8 \%)$ participants were from Hindu religion, 60 (21.2\%) from Islam and 51 (18.0\%) from Christian religion. The participants who belong to tribal ethnicity were $64(22.6 \%)$ and more than half were non-tribal $219(77.4 \%)$.

Table-1: Socio-demographic information of the Participants

\begin{tabular}{|lllll|}
\hline \multicolumn{1}{|c}{ Variables } & & Participants (N=283) & Percentage (\%) \\
\hline \multirow{3}{*}{ Gender } & Male & 152 & 53.7 \\
\cline { 2 - 4 } & Female & 131 & 46.3 \\
\hline \multirow{3}{*}{ Socio economic status } & Upper-class & 17 & 6.0 \\
\cline { 2 - 4 } & Upper-middle & 121 & 42.8 \\
\cline { 2 - 4 } & Lower middle & 112 & 39.6 \\
\cline { 2 - 4 } & Upper-lower & 22 & 7.8 \\
\cline { 2 - 4 } & Lower & 11 & 3.9 \\
\hline Religion & Hindu & 172 & 60.8 \\
\cline { 2 - 4 } & Islam & 60 & 21.2 \\
\cline { 2 - 4 } & Christian & 51 & 18.0 \\
\hline Ethnicity & Tribal & 64 & 22.6 \\
\cline { 2 - 4 } & Non-tribal & 219 & 77.4 \\
\hline
\end{tabular}

Table 2 shows the level of depression, anxiety, and stress among college going student. In the domain of depression there were 229 (80.9\%) participants who had no depression, whereas 27 (9.5\%) had a mild level of depression and the same number i.e., 27 (9.5\%) were having a moderate level of depression. In anxiety 157 (55.5\%) more than half participants did not have anxiety but 61 (21.6\%), $42(14.8 \%), 19(6.7 \%)$ and 4 (1.4\%) participants had mild, moderate severe and extremely severe level of anxiety respectively. The stress level showed that 177 (62.5\%) participants had no stress where 62 (21.9\%) had a mild level of stress and 44 (15.4\%) had a moderate level of stress.

Table-2: Prevalence of Psychological distress (Depression Anxiety and Stress among college students

\begin{tabular}{|llll|}
\hline Variables & Domains & Participants (N=283) & Percentage (\%) \\
\hline Depression & Normal & 229 & 80.9 \\
\cline { 2 - 4 } & Mild & 27 & 9.5 \\
\cline { 2 - 4 } & Moderate & 27 & 9.5 \\
\hline Anxiety & Normal & 157 & 55.5 \\
\cline { 2 - 4 } & Mild & 61 & 21.6 \\
\cline { 2 - 4 } & Moderate & 42 & 14.8 \\
\cline { 2 - 4 } & Severe & 19 & 6.7 \\
\cline { 2 - 4 } & Extremely Severe & 4 & 1.4 \\
\hline Stress & Normal & 177 & 62.5 \\
\cline { 2 - 4 } & Mild & 62 & 21.9 \\
\cline { 2 - 4 } & Moderate & 44 & 15.4 \\
\hline
\end{tabular}


Table 3 shows the level of resilience among college going students. It shows $42(14.8 \%)$ participants had a very high level of resilience and $184(65.0 \%)$ participants had a high level of resilience whereas $46(16.3 \%)$ had the undetermined level of resilience and $2(0.7 \%)$ and $9(3.2 \%)$ had low and very low level of resilience.

Table-3: Level of resilience among college students

\begin{tabular}{|lll|}
\hline Resilience & Participants $(\mathbf{N}=283)$ & Percentage (\%) \\
\hline Very high & 42 & 14.8 \\
\hline High resilience & 184 & 65.0 \\
\hline Undetermined & 46 & 16.3 \\
\hline Low & 2 & 0.7 \\
\hline Very low & 9 & 3.2 \\
\hline
\end{tabular}

Table 4 shows the level of mindfulness among college going students. The $94(33.2 \%)$ participants had a greater level of mindfulness however, $163(57.6 \%)$ had a moderate level of mindfulness and $26(9.2 \%)$ participants had a low level of mindfulness.

Table-4: Level of Mindfulness among College Students

\begin{tabular}{|lll|}
\hline Mindfulness & Participants $(\mathrm{N}=283)$ & Percentage $(\%)$ \\
\hline Low level & 26 & 9.2 \\
\hline Moderate level & 163 & 57.6 \\
\hline Greater level & 94 & 33.2 \\
\hline
\end{tabular}

The correlation between psychological distress, mindfulness and resilience revealed that Psychological distress has significant negative correlation with mindfulness $(r=-0.229 ; p>0.01)$ and resilience $(r=-0.325$; $\mathrm{p}>0.01$ ).

As shown in the regression summary table 5, the regression model that included mindfulness and resilience on overall psychological distress. Both mindfulness and Resilience variable contributed significantly to the prediction of overall stress of college students $(F(2 / 282)=21.20, p>0.001)$ accounting for 1.32 percent variance. The remaining 98.68 percent was attributed to variables not included in the study. Resilience (Beta $=-0.283, \mathrm{t}=-4.857 ; \mathrm{p}=0.0001)$ and Mindfulness ( $($ Beta $=-0.149 ; \mathrm{t}=-2.566 ; \mathrm{p}=0.01)$ strongly contributed to the variance on the overall psychological stress

Table-5: Regression analysis summary of Mindfulness and resilience on psychological distress among college students

\begin{tabular}{|c|c|c|c|c|c|c|c|c|}
\hline Variable & B & Std. Error & Beta & $\mathrm{T}$ & $\mathrm{R}$ & $\begin{array}{l}\mathrm{R} \\
\text { square }\end{array}$ & $\mathrm{F}$ & Sig. \\
\hline Resilience & -0.115 & 0.024 & -0.283 & -4.857 & 0.355 & 0.126 & 21.20 & 0.0001 \\
\hline Mindfulness & -0.067 & 0.026 & -0.149 & -2.566 & & & & 0.01 \\
\hline constant & 16.130 & 1.127 & - & 14.308 & & & & 0.0001 \\
\hline
\end{tabular}

Significant at $p<0.001$ 


\section{DISCUSSION}

In the study, it was found that $9.5 \%$ had a mild level of depression and $9.5 \%$ had a moderate level of depression. In the study $21.6 \%$ had mild anxiety, $14.8 \%$ had moderate anxiety, $6.7 \%$ severe and $1.4 \%$ participants extremely severe level of anxiety. The stress level showed that $62.5 \%$ of participants had no stress where $21.9 \%$ had a mild level of stress and $15.4 \%$ had a moderate level of stress. Previous research has indicated, university students are a population vulnerable to experiencing high levels of perceived stress and psychological distress [13-14]. According to Stallman [14] psychological health problems that result from elevated stress, anxiety, and depression are also most frequently observed between the ages of 18 to 34 years. In resilience $14.8 \%$ participants had a very high level of resilience, $65.0 \%$ had a high level of resilience, $16.3 \%$ had the undetermined level of resilience. In mindfulness $33.2 \%$ participants had a greater level of mindfulness however, $57.6 \%$ had a moderate level of mindfulness and $9.2 \%$ participants had a low level of mindfulness. Resilience has been associated with the motivational drive to recover from adversity, highly disruptive events, and maintain a relatively stable, healthy level of psychological and physiological functioning [15-17]. Research has clearly demonstrated that increased resilience improves an individual's ability to handle and recover from setbacks and challenges $[15,18]$. In general, developing positive human strengths and enhancing resilience has been associated with reductions of psychological distress [17]. Research suggests that building resilience in university students would prevent impairment, given the association between higher levels of resilience and lower levels of psychological distress demonstrated in various studies $[15,17,19]$. In the regression analysis it was found that Resilience and Mindfulness strongly contributed to the variance on the overall psychological stress. Bacchi and Licinio [20] found that higher levels of resilience were associated with lower levels of psychological distress. Mindfulness is a significant predictor of resilience and is associated with lower psychological distress and act as a protective mechanism against stressors. Previous research has demonstrated many positive outcomes associated with enhanced mindfulness, particularly the improvement of psychological well-being and resilience [21-22]. Despite the promising findings from the current study, certain limitations are noted. First, participants' previous experience with mindfulness and meditation was not taken into account. The sample size was small and is unlikely to be representative of the wider student population across.

\section{CONCLUSION}

From the present study, it can be concluded that resilience and mindfulness are significant predictors of psychological distress and act as a protective mechanism against stressors. These findings provide preliminary insight into the need for cultivating resilience in university students and facilitating adaptive coping strategies and mindfulness, which will be intrinsically linked to navigating change and adversity without the deleterious effects of psychological distress. Further studies are required to determine the efficacy of resilience and mindfulness centred interventions in university students.

\section{REFERENCES}

1. Dyson R, Renk K. Freshmen adaptation to university life: Depressive symptoms, stress, and coping. J Clin Psychol 2006;62(10):1231-44.

2. Foster J, Allen B, Oprescu FI, McAllister M. Mytern: an innovative approach to increase students' achievement, sense of wellbeing and levels of resilience. J Austr NZ Stud Serv Assoc 2014;43:31-40.

3. Keye MD, Pidgeon AM. Investigation of the relationship between resilience, mindfulness, and academic selfefficacy. Open J Soc Sci 20132;1(6):1.

4. Thompson RW, Arnkoff DB, Glass CR. Conceptualizing mindfulness and acceptance as components of psychological resilience to trauma. Trauma Viol Abuse 2011;12(4):220-35.

5. Hjemdal O, Friborg O, Stiles TC, Rosenvinge JH, Martinussen M. Resilience predicting psychiatric symptoms: A prospective study of protective factors and their role in adjustment to stressful life events. Clin Psychol Psychother 2006;13(3):194-201.

6. Stallman HM. Embedding resilience within the tertiary curriculum: A feasibility study. High Educ Res Dev 2011;30(2):121-33. 
7. Klohnen EC, Vandewater EA, Young A. Negotiating the middle years: Ego-resiliency and successful midlife adjustment in women. Psychol Aging 1996;11(3):431-8.

8. Swanson J, Valiente C, Lemery-Chalfant K, Caitlin O'Brien T. Predicting early adolescents' academic achievement, social competence, and physical health from parenting, ego resilience, and engagement coping. J Early Adolesc 2011;31(4):548-76.

9. Pidgeon AM, Keye M. Relationship between resilience, mindfulness, and pyschological well-being in University students. Int J Liberal Arts Soc Sci 2014;2(5):27-32.

10. Lovibond PF, Lovibond SH. The structure of negative emotional states: Comparison of the Depression Anxiety Stress Scales (DASS) with the Beck Depression and Anxiety Inventories. Behav Res Ther 1995;33(3):335-43.

11. Walach H, Buchheld N, Buttenmüller V, Kleinknecht N, Schmidt S. Measuring mindfulness-the Freiburg mindfulness inventory (FMI). Personal Individ Diff 2006;40(8):1543-55.

12. Block J, Kremen AM. IQ and ego-resiliency: conceptual and empirical connections and separateness. J Personal Soc Psychol 1996;70(2):349-54.

13. Larcombe W, Finch S, Sore R, Murray CM, Kentish S, Mulder RA, Lee-Stecum P, Baik C, Tokatlidis O, Williams DA. Prevalence and socio-demographic correlates of psychological distress among students at an Australian university. Stud High Educ 2016;41(6):1074-91.

14. Stallman HM. Psychological distress in university students: A comparison with general population data. Austr Psychol 2010;45(4):249-57.

15. Abbott JA, Klein B, Hamilton C, Rosenthal AJ. The impact of online resilience training for sales managers on wellbeing and performance. Sensoria: A Journal of Mind, Brain and Culture 2009;5(1):89-95.

16. Herrman H, Jané-Llopis E. The status of mental health promotion. Pub Health Rev 2012;34(2):6-12.

17. Steinhardt M, Dolbier C. Evaluation of a resilience intervention to enhance coping strategies and protective factors and decrease symptomatology. J Am Coll Health 2008;56(4):445-53.

18. Reivich K, Shatté A. The resilience factor: 7 essential skills for overcoming life's inevitable obstacles. Broadway Books; 2002.

19. McCann A, Hicks RE. Resilience in university students: Academic success, recollected parental style, and coping strategies. In Wayfinding through life's challenges: Coping and survival 2011 (pp. 485-500). Nova Science Publishers.

20. Bacchi S, Licinio J. Resilience and psychological distress in psychology and medical students. Acad Psychiatry 2017;41(2):185-8.

\author{
Acknowledgements - Nil \\ Funding - Nil \\ Conflict of Interest - Nil
}

$* * * * * * * * * * * * * * * * * * * * * * * * * * * * *$ 